\title{
Communicating CSR: Case Study of Japanese Food Industry
}

\author{
Kaori Takano ${ }^{1}$ \\ ${ }^{1}$ School of Business Administration, Fort Lewis College, USA \\ Correspondence: Kaori Takano, School of Business Administration, Fort Lewis College, Durango, CO 81301, \\ USA. Tel: 1-970-247-7060. E-mail: kaoringcun@yahoo.com
}

Received: February 19, 2013

Accepted: March 18, 2013

Online Published: April 14, 2013

doi:10.5539/ijbm.v8n9p111

URL: http://dx.doi.org/10.5539/ijbm.v8n9p111

\begin{abstract}
This study examines how the Japanese food industry responded to the food education law of 2005 through corporate social responsibility (CSR) communication. No previous study has examined factory visits and food education of the Japanese food industry as social responsibility activity in the light of the new food education law in Japan. Corporate websites of all the food companies categorized in the food industry in Japan were examined during the period 2009 December to 2010 March: A total of 275 companies, 139 publicly traded and 136 unlisted. Examined were the availability of factory visits, CSR reports, and food education lessons conducted at schools. Unlike a positive report from a study conducted by the government, the majority of the Japanese food industry appears to be struggling to meet the social needs of food education and has failed to establish effective CSR communication channels with stakeholders. This study contradicts a government survey report and reveals the food industry did not appear to respond well to the food education law. The industry, however, may have engaged in an implicit CSR approach considering the positive outcomes of the national movement of food education, promoted by the food education law.
\end{abstract}

Keywords: corporate social responsibility (CSR), communication, public policy, public health, corporate curriculum, Japan

\section{Introduction}

Obesity, for decades, has been a major health issue worldwide. Japan, regarded as one of the healthiest nations in the world, appeared to be an exception to this trend. Even as recently as 2009 in a report of the Organisation for Economic Co-operation and Development (OECD), the prevalence of obesity in Japan was only 3.4\%, the lowest of all nations, in contrast with 34.3\% for the United States (as cited in Mar, 2010). This does not mean that Japan has always been the exception. In the 1980s, researchers recognized children's unhealthy diets that were due to the prevalence of western food and the overall fading of traditional Japanese food culture. Researchers called for the establishment of food education especially for young children (Iwasawa, 1987; Kireruko, 2000; Kodomoga, 1999; Konaiboryoku, 1985; Sugihira, 1999). The entire society became convinced that food education was an emergent social need. Additionally, the Ministry of Education, Culture, Sports, Science and Technology of Japan (MEXT) reported that the percentage of 6th grade boys who were overweight doubled to more than $11 \%$ by 2002 compared to the late 1970s (MEXT, 2003). The national government increasingly became proactive regarding this issue. According to the Shokuiku Hakusho (food education white paper), the need for shokuiku or food education emerged in the society due to the growing concern regarding the unhealthy diets of Japanese citizens, especially that of children (Cabinet Office Government of Japan, 2006b).

In order to cope with the problem of unhealthy diets of Japanese citizens, the Shokuiku Basic Act, Shokuiku Kihon Hou, was enacted in June 2005. According to the Basic Program for Shokuiku Promotion (Cabinet Office Government of Japan, 2006a), Shokuiku or food education is defined as "the foundation for living, and positions it as the base of intellectual (Chiiku), moral (Tokuiku) and physical (Taiiku) education" (2006a, p.1). The goal is for the people to "have the ability to select proper food through a variety of experiences, and thus to nurture people to realize healthy food habits" (Cabinet Office Government of Japan, 2008, p. 2). The creation of this new food education law led to a significant discussion evidenced in the number of newspaper articles that reported on the importance of food education in the past decade (see Figure 1). 


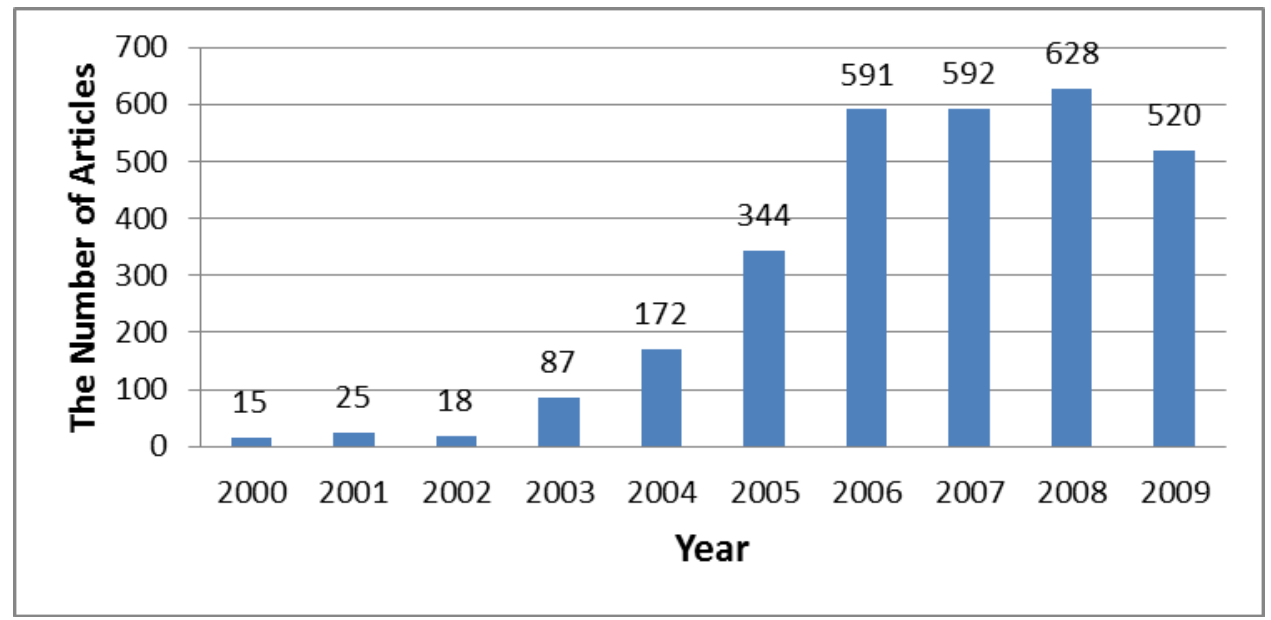

Figure 1. Number of newspaper articles regarding food education

Source: Kikuzo II, the Asahi Shimbun News Database.

\section{Background}

\subsection{Food Education as CSR}

As part of the Basic Shokuiku Act, the government developed a Shokuiku (food education) promotion basic plan to be carried out for five years from fiscal years 2006 to 2010. The 2006 basic plan promoted interaction between food producers and consumers (Cabinet Office Government of Japan, 2006a, p. 5), and the food companies were expected to "voluntarily and actively promote Shokuiku in their business operations, while making sincere efforts to cooperate with the national and local government measures on Shokuiku promotion" (Ministry of Agriculture, Forestry and Fishery, n. d., p. 5). The word was changed from "voluntarily" to "required" in the Shokuiku White Paper (Cabinet Office Government of Japan, 2008) as follows.

[Food companies] are required to provide opportunities for various hands-on activities, products and menu that take health into account, and information and knowledge about diets.....provide activities such as field observation of the production lines and shops (p. 16).

Field observations of the production lines are called factory visits. Usually, factory visits require reservations, but they are free of charge and open to the public. This is one of the most recognized corporate involvements in public education in Japan. The 2009 Shokuiku White Paper reported on the importance of these experience-based activities including school excursions and further stated, "Factory visits that have been offered by the industry should be promoted and expanded along with green tourism and industry tourism" (Cabinet Office Government of Japan, 2009a, p.18). This statement indicates that the government recognized the presence of factory visits in the industry, and that its expectation toward the food industry in terms of food education was extremely high. The very first Shokuiku Hakusho, or Food Education White Paper published in 2006 explained that some companies position factory visits and food education programs as corporate social responsibility (CSR) activities and others as marketing strategies (Cabinet Office Government of Japan, 2006b, p. 64). This indicates that the government was fully aware that food education could be used as a business marketing strategy.

\subsection{Government Report}

In order to assess the promotion of food education in the private sector, the Cabinet Office Government of Japan (2009b) conducted a survey in 2008. Six hundred companies, 200 food manufacturers, 200 food retailers, and 200 food service providers were contacted and 167 companies responded to the survey. The overall response rate was $27.8 \%$. Of those companies, 66 companies or $39.5 \%$ are food manufacturers and the rest are food retailers and food service providers. One hundred thirty-six companies (81\%) of 167 reported that their capital amount is more than 100 million yen (approximately 1.25 million dollars), and 76\% reported that their years in business are more than 30 . Asked if the company engages in food education, $79 \%$ or 132 companies answered "yes" including some that intended to implement it the same year. Furthermore, 50\% answered that they provide food education information on their websites, and $44.7 \%$ answered that they engage in industry tourism including factory visits as food education programs. These companies were also asked why they initiated food education. The number one 
reason $(50 \%)$ was because they recognized the growing public concern about food safety and the heightened awareness about food in general. The second reason was CSR (37.9\%), and other reasons were customer satisfaction (36.4\%), marketing strategy (28.0\%), customers' preference for health orientation (28\%), and 25.8\% answered the reason was the Shokuiku Basic Act (Cabinet Office Government of Japan, 2009b, p. 3-4).

Of the food manufacturers, $65.4 \%$ answered that their company provides food education information on their websites, and $61.5 \%$ answered their company engages in industry tourism including factory visits as part of a food education program. The primary reason for food education programs was CSR as identified by $55.8 \%$ of the food manufacturers in the survey. This indicates more than half the food makers engaged in food education and the primary reason was CSR (Cabinet Office Government of Japan, 2009b).

It is important to note that this government survey did not capture several aspects. First, it was a self-report survey. Therefore, the actual promotion of food education may not be consistent with the survey results. Second, the response rate among food manufacturers was relatively low at 33\% (66 out of 200 companies). Because the top 200 food manufacturers were selected and targeted as potential participants based on the amount of sales (Cabinet Office Government of Japan, 2009b, p. 2), the survey results tended to rely on data provided by only established and profitable companies. Therefore, small and mid-sized businesses in the food industry appear to be excluded. Third, factory visits can be offered by only food manufacturers, not retailers or food service providers. In the survey, only 66 food manufacturers responded. There were, at the time, 275 manufacturers in the food industry in Japan. Therefore, the majority of food manufacturers were excluded in the survey and little is known regarding the reality of factory visits in the food industry. Fourth, the government survey number included companies who intended to initiate food education in 2008. This creates a reasonable doubt that some may not have initiated it in or after 2008 as intended. Due to these reasons, there was a realization that few studies, if any, since 2008 have examined the availability of factory visits and food education programs as CSR activities in the Japanese food industry.

\section{Corporate Social Responsibility and Globalization}

The past decade, corporate social responsibility (CSR) became globalized and a growing demand and expectation from society pushed corporations to place CSR at the core of their activities (Chapple \& Moon, 2007; Okamoto, 2008; Podnar, 2008; Porter \& Kramer, 2006). Naturally, CSR communication has received great attention from scholars and managers in recent years in order to effectively communicate CSR with stakeholders.

Researchers have studied CSR communication around the world. A study in Hungary found that a short-term profit orientation and lack of strategy created difficulties in CSR communication (Ligeti \& Oravecz, 2009). Morsing, Shultz and Nielsen (2008) studied CSR communication in Danish settings and pointed out that European companies prefer an implicit CSR approach whereas US companies expect an explicit CSR approach, while recognizing a shift having occurred from an implicit to explicit CSR approach. They further implied that over-communicating CSR practices is not well received in Denmark and that communicating CSR via third party experts is regarded as effective communication because companies want to avoid appearing as self-serving organizations in the public eye (Morsing et al., 2008, p. 107). Another Danish study shed light on a different side of the Danish business community. According to Nielsen and Thomsen (2009), small and medium-sized companies had no interest in communicating CSR externally and no strategy for CSR communication, indicating small and medium-sized companies have a long way to go for learning how to communicate CSR.

Researchers who studied CSR in emerging global markets and non-Western countries provided insights regarding CSR communications. For example, Logsdon, Thomas, and Van Buren (2006) studied CSR of large Mexican firms and argued that the Mexican CSR was not brought in by US firms and that it does not reflect the patterns of US or Western European firms. They argue that their CSR is uniquely rooted in the history and the culture of Mexico and that the significant expectations from society led Mexican firms to engage in direct interactions with stakeholders and focus on community involvement. Chaudhri and Wang (2007) studied the web-based CSR communication of the top 100 information technology companies in India. They found a significant absence of CSR communication on the websites and India-specific CSR information was minimal even for US corporations conducting business in India. The study also indicated room for improvement of CSR strategies to enhance dialogue between a company and its stakeholders in India. Soboleva (2007) studied Russian CSR and found that wage issues were the most important problem and that demanding CSR beyond a basic level would be inappropriate at this time. The society expects government, not business, to alleviate social conflicts, and the government provides no real incentives for socially responsible behavior in Russia (Soboleva, 2007, p. 89). Therefore the concept of CSR which was dominated by US and European perspectives was challenged in different parts of the world. Tang and Li (2009) studied CSR communication of leading Chinese and global companies 
operating in China and explained that some corporations and scholars in China reject the concept of CSR, claiming that "The Western notion of CSR represents a western hegemony and a conspiracy of developed countries to circumvent the growth of the Chinese economy" (cited in Tang \& Li, p. 202). They claimed that the most global CSR studies are still based on a western paradigm, which may not be useful in understanding of CSR in different countries. Keeping this concern in mind, it is relevant to examine corporate social responsibility within the Japanese context.

\section{CSR in Japanese Context}

Japanese CSR has received relatively little academic attention because emerging economies have attracted more attention and that most Japanese CSR studies tend to be conceptual and lack empirical analysis (Fukukawa \& Teramoto, 2009, p. 134-135). The cultural and historical aspects of Japanese CSR is presented here with a focus on empirical evidence in order to provide better understanding of CSR in the Japanese context.

\subsection{Cultural Aspect}

First, Japan is a collectivist society. As an established anthropologist, Gary Ferraro (2010) puts it, collectivist societies have a strong sense of responsibility to the group such as country, family, and company and, "success and failure are "team affairs' in Japan" (p. 112). McMillan (1996) pointed out that the Japanese government planning provides a consistency between public policy goals and private corporate objectives and "business and government share the same goal of making Japan internationally competitive" (p. 80). As previously stated, the Shokuiku Basic Act was established in 2005 and the government expected food companies to work with the public sector to provide experience-based activities to promote food education. The success of food education was to rest on team work among government, people and the food industry in Japan, as suggested by the Shokuiku Basic Act.

Second, Japan is a high-context culture. According to McFarlin and Sweeney (2011), much detailed or explicit information is not required or expected in a high-context culture because people are concerned with long-term relationships, reputation and establishing trust over time. In contrast, it is common in a low context culture like the United States for communications to be explicitly stated and discussed because, for Americans, spelling out corporate activities on their websites is merely a business necessity (McFarlin \& Sweeney, 2011, p.166). This cultural difference is translated a great deal into business practices. The difference tends to be reflected in corporate reports. For example, Americans have shown a typical self-serving bias, the tendency to take credit for success but to blame failure on other causes, whereas the Japanese are less likely to take credit for success. Consequently, the US reports tend to provide a much more positive view of firm performance than do Japanese reports (McFarlin \& Sweeney, 2011, p. 171). This may explain why American corporations tend to spell out positive activities such as CSR whereas Japanese corporations tend to be conservative about proclaiming "doing good" for the society.

\subsection{Historical Aspect}

The historical aspect of Japanese CSR practices should be addressed. The origin of the Japanese CSR principle can be traced back to the 17 th century of the Edo Period when many business leaders established a strong presence in the community (Okamoto, 2008; Tanimoto, 2006). Many of the Edo period business leaders believed in co-existence with the society and operated their businesses with the fundamental principle "put your public benefit over your own business interest" (Okamoto, 2008, p. 31).

Examples of public benefit from the educational arena may explain why Japanese food companies established their CSR activities. CSR activities in education occur primarily in three forms in the Japanese food industry: factory visits, non-profit organizations, and donations of educational materials. Factory visits are very common for Japanese manufacturers, especially food makers, to offer to schools. This involvement has existed for decades in Japanese education. For example, Keenleyside and Thomas (1937) highlighted school excursions as an objective Japanese teaching method in order to satisfy children's curiosity. They explained that these school excursions include business as follows:

In order that the children may learn how business and industry are carried on, school visits are arranged to business-houses, commercial establishments, industrial plants, railway stations, docks and other essential units in the life of a modern state (p. 186).

They further pointed out that the Japanese government plays an active role in facilitating factory visits for children.

Another form of CSR is that of non-profit organizations housed within companies. One of the examples is Ezaki Glico, a well-established and very popular candy maker in Japan. The founder Riichi Ezaki believed that commercial activities must be the ones that benefit the society and the company should give back to the 
community once it becomes profitable. Ezaki spoke to government officials, medical doctors, and educators in order to promote health for mothers and children. In 1934, he successfully established a foundation called "the Mother and Child Health Foundation." The foundation has promoted science-based food education, good diets, and good health through education (Mother and Child Health Foundation, 2009). It is important to note that one of the important stakeholders for Ezaki was government officials.

Another form of CSR is the donation of educational materials based on corporate philosophy and core values. Kagome, a leading ketchup maker in Japan is a good example. The company started food education for children in 1964 and donates educational materials to preschools. Kagome also started in 1999to donate baby tomato plants nationwide to elementary schools. The company sends plants to approximately 4,000 schools including elementary schools, preschools, and special needs schools for use in science projects or food education programs (Kagome, 2009). In Japan, public schools account for 97.5\% of the elementary schools (Ministry of Education, Culture, Sports, Science and Technology of Japan [MEXT], 2010), unlike their American counterpart. Therefore, the chief beneficiary of Kagome's donation is public elementary schools.

These are a few examples of Japanese CSR in the education arena within the public domain. Even though it is said that corporate Japan actively geared into CSR activities after 2003 (Japan Business Federation, 2007; Tanimoto, 2006), the origin of the Japanese CSR principle, co-existence with society, can be traced back to the Edo period business leaders of the 17th century. The principle flourished along with economic development in the $19^{\text {th }}$ century and some companies, as stated, had strong presence with visible CSR in the mid 20th century.

\subsection{Previous Japanese CSR Studies}

Wokutch (1990) studied the early stages of CSR management of Japanese companies operating in the United States. He pointed out cultural values such as group harmony, confucianism and loyalty that helped companies develop cooperative relationships with stakeholders such as employees and authoritative agencies. It is noteworthy that Wokutch recognized that the success of Japanese CSR management in the United States was due to the concerted efforts of the Japanese firms, their industry associations, and the Japanese government on influencing public opinion in the United States (Wokutch, p.72). In the mid 1990s, Japanese manufacturers in international business played a larger role incorporating CSR to Japanese business community (Tanimoto, 2006). However, cultural norms operating in Japanese business appeared to invite "unintended and serious implications for the effects of some CSR activities" (Higgins \& Debroux, 2009, p. 127).

Fukukawa and Moon (2004) examined CSR reports of the top 50 Japanese companies and found out that $96 \%$ have CSR units and 90\% claim regular CSR reporting. Tokoro's study (2007) revealed, unlike US and European companies, that many Japanese managers believe it may be inappropriate for Japanese companies to take a formal objective approach for stakeholder dialogue for the purpose of value creation. Fukukawa and Teramoto (2009) interviewed global managers of 13 Japanese multinational corporations from different industries and recognized that the Japanese modes of CSR are different from the Anglo-American approach. They reported that Japanese corporations believe that "CSR should not need to raise its voice.... when CSR is infused throughout an organization" (p. 139) while recognizing that globalization is now reshaping CSR practices in Japan. Their study suggests that Japanese corporations still practice the implicit CSR communication approach, unlike the explicit approach highly valued by the Anglo-American business community.

This research addressed three concerns raised by previous studies on CSR communication. First, many CSR studies tend to focus on large companies. More research is needed to address CSR in small and medium-sized companies to bring out the total reality of CSR. Second, the simple application of the Anglo-American approach may not be appropriate for understanding CSR communication in non-Western countries and the cultural differences should be carefully considered. Third, the industry as a whole may be a significant predictor of CSR communication compared to using national boundaries. Industries which deal with consumers, not business clients, tend to be more concerned about positive public images (Tang \& Li, 2009). Chaudhri and Wang (2007) selected an industry in India for their study of CSR because of the pivotal role in the national interest. Consequently, the selection of an industry that cares about a positive public image is crucial, and additionally so is the national interest.

Taking this into account, this study attempts to capture a valid picture of CSR communication of the food industry in Japan by examining all companies including small and mid-sized companies, through the lens of food education as a nationally recognized social need. As indicated, previous studies have focused on the top companies or multinational corporations across industries, and CSR in the non-Western context is still under-researched. It remains unknown regarding the realities of specific industries or that of small and mid-sized companies in Japan. Therefore, this study attempts to provide insights as to Japanese CSR communication through an examination of 
the websites of all companies in the food industry in Japan.

\section{Purpose of Study}

The purpose of this study was to examine the availability of factory visits, food education programs, and CSR reports in the food industry in Japan. These are good indicators of effective CSR communication, which also suggests how well the food industry responded to the new food education law. Three primary research questions were asked: How available are factory visits in the food industry in Japan? How available are food education programs for school aged children offered by the food industry in Japan? How effectively are CSR activities communicated with stakeholders? I hypothesized that, unlike the government report, the Japanese food industry did not respond well to the new food education law. Answering the above three research questions through this investigation will provide insights regarding CSR communication of the Japanese food industry and the national movement for food education.

\section{Methodology}

Corporate websites of all the food companies categorized in the food industry in Japan were examined. As of December 2009, there were 275 companies in the food industry category in a widely recognized business publication in Japan, Kaisha Shiki Ho (Toyo Keizai Shimpo Sha, 2009a, 2009b). The food industry consists primarily of food manufacturers. Included were 139 listed companies whose stock was publicly traded and 136 that were unlisted. In order to see differences, the companies were categorized into two: Listed and unlisted. All of the companies had websites. The availability of factory visits, food education programs including corporate lessons conducted at schools, and CSR reports were examined based on the information from company websites during the period December 2009 to April 2010. Factory visits are actual tours for observation of the manufacturing lines. Virtual factory tours on the websites were not counted as factory visits. Food education programs were identified when the researcher was able to identify a section of Shokuiku or food education on the websites and where knowledge about food choice, food safety, and healthy diets was addressed.

This study uses the framework of Kyouji Okamoto's communication channels to examine CSR of the food industry in Japan. Okamato (2008) claims that CSR is a key to social change requiring four different communication channels: Identification of social needs, scientific data regarding ecology, dissemination of CSR information, and communication with stakeholders (p. 120-121). This study did not attempt to address the communication channels of scientific data used by the Japanese food industry. It, however, captured the big picture of the other three. The first channel addresses how well the Japanese food industry responded to the social need, for food education, by examining the availability of factory visits and food education programs. The second channel, dissemination of CSR information, involves how effectively the industry communicates CSR activities such as factory visits and food education programs on their websites. The third channel involves the availability and transparency of factory visits and food education lesson plans for educators because they may be used as an indicator of effective communication with stakeholders. Using these three channels, the social responsibility communication of the Japanese food industry was examined.

\section{Findings}

\subsection{About the Food Industry in Japan}

As for the 139 listed companies, 45 companies primarily produced ready-to-eat food (33\%), 32 companies produced ingredients such as flour (23\%), 25 drink companies (18\%), 17 companies were producing snacks (12\%), 17 companies produced seasonings such as soy sauce (12\%), and three companies that produced other things such as preservatives and chemicals $(2 \%)$.

As for the 136 unlisted companies, 33 companies produced ready-to-eat food (24\%), 28 companies were snack makers (20\%), 24 produced seasoning (18\%), 20 produced ingredients (15\%), 16 were drink makers $(12 \%)$, and 15 companies produced other (11\%). Aggregate data for the food industry are presented in Figure 2. 


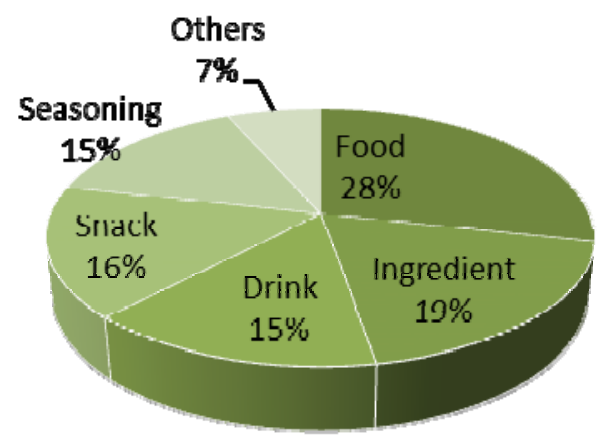

Figure 2. Japanese food industry by product category

\subsection{Factory Visits}

One of every five companies (21\%) in the food industry offer factory visits that are open to the public: 34 listed companies (24\%) and 24 unlisted companies (18\%). Upon the examination of the content of the factory visits, the websites show that 12 of the 34 listed companies disclosed the program content and indicated that factory visits also include watching video clips. Only 4 of 24 unlisted companies disclosed the program content and included video clips in their factory visit programs.

\subsection{Food Education Programs and Lessons at Schools}

Out of 275 food companies in the industry, $18.5 \%$ or 51 companies (23 listed and 28 unlisted) have food education programs on their websites. Of these, 19 companies (11 listed and 8 unlisted) offered food education lessons at schools. The majority of these 19 companies is well recognized and established including world leaders. The listed companies who offered food education lessons at schools are as follows: Six seasoning makers (soy sauce, Japanese seasoning, ketchup, mayonnaise, spice, salad dressing), three milk producers, one ham maker, and one producer of flour. Eight unlisted companies that offered food education lessons at schools included two food makers, two snack makers, one milk producer and one each of producers of seasonings, pickles and water. Based on the examination of the content of their food education lessons, 7 out of 11 listed companies and 7 out of 8 unlisted companies, in total 14 (73.7\%) out of 19 companies that offered food education lesson at schools, did not disclose detailed lesson plans on their websites.

\subsection{CSR Websites and CSR Reports}

On examination of the corporate websites, 51 (37\%) of the 139 listed companies have CSR websites whereas 28 (21\%) out of 136 unlisted companies have CSR websites. Of those 32 listed companies (23\%) have CSR reports on their websites, whereas, only 6 unlisted companies (4.4\%) have CSR reports on their websites. In total, approximately $29 \%$ of the companies in the food industry have CSR websites. However, only approximately $14 \%$ in the industry have CSR reports on their websites.

\section{Discussion}

This section addresses the findings in relation to the three communication channels, difference in categories, and food education law and Japanese society.

\subsection{First Channel: Identification of Social Needs}

This study revealed that the majority of food makers are not offering factory visits or food education programs. Food education was one of the most important social needs identified by Japanese society in the early 21 st century and evidenced in the Shokuiku Basic Act. As of March 2010, only 21\% of the food industry offered factory visits and $18.5 \%$ (51 companies) had responded to the social needs and established food education programs. It suggests that the majority of the food companies were either not interested in being involved with food education programs, or were still searching for the best way to provide food education. In defense of these companies, it is understandable that some may have decided not to be involved in food education programs due to the nature of their primary products. For example, it is easy for a milk producer to talk about the nutritional value of milk, using its products. It is reasonable to assume that it is difficult for a salt maker, flour or oil producer, to discuss nutritional values and food choices. Considering the fact that more than half of the industry is in the category of ready-to-eat foods, drinks, and snacks, only $18.5 \%$ of the food companies have responded to the social needs, which indicates that the industry has not responded well to the social needs for food education. 
Furthermore, only 19 of 275 companies (approximately 7\%) were capable of visiting schools to provide food education lessons. These are well-established and recognized companies including Kikkoman and Ajinomoto, who tend to be financially stable and able to hire the necessary staff to support food education activities. The survey conducted by the Cabinet Office Government of Japan (2009b) revealed that while approximately $77 \%$ of the food companies claimed that they recognized a positive impact on their business, many companies identified difficulties of food education such as being understaffed to support food education programs (42\%), inconsistent awareness among employees (37.9\%), lack of food education experts within the company (33.3\%), the activity does not help their business (23.5\%), and a lack of food education information (20.5\%). This study, unlike that of the government, included small and mid-sized businesses and revealed only $20 \%$ engaged in food education. Consequently the challenges faced by the industry, as a whole, may be greater than previously portrayed.

\subsection{Second Channel: Dissemination of CSR Information}

Availability of information regarding CSR activity on company websites is a good indicator of the effective communication of CSR activity. Approximately $29 \%$ of the companies in the food industry have CSR websites but only $14 \%$ have official and detailed CSR reports. This low number indicates that stakeholders including school teachers, customers, and investors have minimal access to CSR reports. Fukukawa and Moon (2004) explained that the absence of CSR communication does not necessarily mean non-CSR activity. However, it becomes misleading if no claim was made (p. 48). Considering that several years have passed since 2003 when the Japanese business community geared into CSR activities (Japan Business Federation, 2007; Tanimoto, 2006), this study suggests that the Japanese food industry still has a long way to go to effectively disseminate CSR information.

\subsection{Third Channel: Communication with Stakeholders}

In terms of effective communication with stakeholders, lack of information regarding food education becomes apparent when examining the availability of factory visits and food education programs for children. Only $21 \%$ of the food industry offered factory visits. Therefore the majority of food manufacturers do not allow stakeholders to access factory visits and allow observation of the production lines. Furthermore, 14 out of 19 companies that visit schools to provide food education programs failed to disclose in detail their lesson plans. This may be an additional obstacle for school teachers who want to provide food education by working with food makers. School teachers need to know available dates, program contents, and contact information for the factory visits and the food education lessons in order to make informed decisions. In the current form, teachers must make phone calls or write emails to contact the company and obtain this information creating an additional burden. This leaves significant room for improvement in the social business practices of the Japanese food industry. Efficient collaboration between educators and the business community will occur with the expansion of the factory visit programs and additional disclosure of information about factory visits and food education lessons.

\subsection{Difference in Listed and Unlisted Categories}

This study suggests, as expected, that listed companies tend to be stronger CSR communicators. Among listed companies, $24 \%$ provide factory visits compared to $18 \%$ of unlisted companies. Because factory visits require both financial and physical resource allocation, it makes sense that listed companies have a higher percentage. Additionally, because providing food education information on websites costs less, compared to providing factory visits or food education programs at schools, unlisted companies have a higher percentage of having food education programs on their websites. As for CSR communication, more listed companies actively communicate CSR activities on their websites (37\%) compared to unlisted companies (21\%). Similarly, more listed companies present CSR reports (23\%) on their websites, compared to unlisted companies $(4.4 \%)$. It is apparent that listed companies are better CSR communicators in the Japanese food industry.

\subsection{Food Education Law and Japanese Society}

When Japanese CSR is discussed outside the country of Japan, for the most part, focus is placed on leading or major multinational corporations. A German information portal called "CSR WeltWeit-German Business Global Citizen" claims that Japan is significantly ahead of the Western industrialized countries in terms of CSR, however, interest in the social aspects of CSR is significantly less pronounced than in other industrialized countries (cited in CSR WeltWeit, 2012). The previously discussed cultural differences in communication may explain the absence of CSR communication in Japan despite the growing pressure in this age of accountability. Japan may evidence less interest in social aspects of CSR than other countries, however, this does not mean Japanese CSR has less of a social aspect. Despite the fact that this study contradicts the findings of the government survey which reported corporate food education activity in a positive light, it is arguable that the fact that every one of five companies provides food education through factory visits or educational programs for free of charge manifests a strong interest in the social aspects of CSR. At the same time, however, the absence of CSR communication may be 
misleading and this should be addressed to improve effective dialogue with stakeholders. Because Japanese corporations tend to practice implicit CSR communication approaches, they may consider new and creative ways to communicate with stakeholders.

This new food education law or Shokuiku Basic Act of 2005 is considered as very unique and unprecedented in the world because it was the product of collaborative work of multiple ministries of the Japanese government in order to improve the diets of Japanese nationals of all ages as a national movement (The Mother and Child Health Foundation, 2006). The positive impact of this food education law seems to be greater than it initially appeared because the data collected by the Ministry of Education showed that the trend of overweight children was finally reversed in 2009 after more than two decades and overall the percentage of overweight children then continued to decline (Himan no ko, 2009; MEXT, 2012). As indentified by scholars, due to the nature of collectivist societies, Japan has a strong sense of responsibility to the entire society including governments, companies and families, and the Japanese government tends to provide a consistency between public policy goals and private corporate objectives (Ferraro, 2010; McMillan, 1996). It is reasonable to say that this food education law is the driver behind the successful team work of food education as a national movement in Japan. Interestingly, on the surface, the Japanese food industry did not seem to have responded well to the food education law and the emerging social needs. However, the industry might have contributed to the success of this new food education law, but it possibly received little publicity despite positive outcomes, due to the nature of the high context and collectivistic culture of Japan. They may simply be practicing implicit CSR communication approaches.

\section{Conclusion and Practical Implications}

Contrary to a government survey conducted in 2008 , the reality is that the Japanese food industry was not responding as much as the government expected to the social needs for food education. It provides a different picture of the Japanese food industry in terms of the promotion of food education. This study reveals that the majority of food companies are not effectively disseminating CSR information. They are either not interested in communicating their CSR activity with stakeholders through their websites, or possibly they are just ineffective or struggling to establish CSR communication channels with stakeholders. The government survey indicated that more than half of the food makers engaged in food education and the primary reason was CSR. Clearly, the findings of this study significantly contradict those results.

Accordingly, this study suggests that there is significant room for improvement because CSR communication channels are not fully incorporated into the management of the food industry. Either these companies do not have CSR activities, or if they do, they do not effectively communicate their activities with stakeholders. Therefore, there are several practical implications. First, more food makers may consider the use of website reporting and take advantages of effective dialogue with stakeholders such as educators because there is a recognized need for food education in the country. Second, companies may pursue new and creative ways to communicate with stakeholders, if they choose not to report on their websites. For example, they may want to establish a communication channel exclusively with school teachers. This way, their food education activities may be recognized and endorsed by the public domain. Third, many food companies may have already missed significant opportunities in the face of the national movement of food education in Japan. They should recognize that CSR provides opportunities to work with the public domain such as public schools and local governments, where corporate presence was not necessarily welcomed in the past especially in the compulsory education arena (Takano, 2012). Therefore, it is important for the private sector, especially for small and medium-sized companies, to become more visible because this may open the door to new markets and creates new business opportunities in collaboration with the public domain. Simply put, this study indicates that the Japanese food industry still has a long way to go to fully incorporate CSR into their management and social business practices and to effectively communicate their CSR with stakeholders. Consequently, this study indicates that many companies who engage in CSR without effective communications may be losing a significant market opportunity. Finally, this study suggests that the lack of CSR communication does not mean lack of CSR activities, and the Japanese food industry may be a good example of Corporate Japan still engaging in implicit CSR approaches. It also indicates that the national movement of food education was successful and the impact of the food education law was in fact significant, evidenced by the most recent statistics. This is a good reminder for law and management scholars in the world that all corporate social responsibility activities may not need to be recognized and publicized to be effective in high-context cultures like Japan.

\section{Research Limitations and Direction for Future Research}

There are several limitations in this study. First, because this is a case study of the Japanese food industry, the findings may not be applied to other industries, and other countries. Second, the information obtained relied on 
website reporting. Because Japan is a high context culture, the absence of reporting does not mean the absence of action, as suggested by Japanese CSR scholars. Third, this study did not answer why the majority of the food makers chose not to actively engage in CSR communications regarding their factory visits or food education programs. Further research is recommended to examine why some companies chose not to report CSR activity in Japan. New findings, along with this study, may provide insights for global managers who anticipate CSR in non-Western countries.

\section{References}

Cabinet Office, Government of Japan. (2006a). Basic program for shokuiku promotion [Abstract]. Retrieved from http://www8.cao.go.jp/syokuiku/about/pdf/plan_ol_eng.pdf

Cabinet Office, Government of Japan. (2006b). Heisei 18nenndo ban shokuiku hakusho [Food education white paper 2005]. Tokyo, Japan: Jigaho sha.

Cabinet Office, Government of Japan. (2008). FY 2007 Shokuiku promotion policy: Shokuiku white paper. Retrieved from http://www8.cao.go.jp/syokuiku/data/whitepaper/2008/en/pdf/s1-1.pdf

Cabinet Office, Government of Japan. (2009a). Heisei 21 nendo shokuiku hakusho [Shokuiku white paper 2009]. Retrieved from http://www8.cao.go.jp/syokuiku/data/whitepaper/2009/pdf-honbun.html

Cabinet Office, Government of Japan. (2009b). Kigyobunya tou ni okeru shokuiku suishin no jittai bunsek chousa [The result of survey and analysis in the promotion of food education in corporate sector]. Retrieved from http://www8.cao.go.jp/shokuiku/more/research/r_kekka/index_p.html

Chapple, W., \& Moon, J. (2007). Introduction: CSR agendas for Asia. Corporate Social Responsibility and Environment Management, 14(4), 183-188. http://dx.doi.org/10.1002/csr.159

Chaudhri, V., \& Wang, J. (2007). Communicating corporate social responsibility on the Internet: A case study of the top 100 information technology companies in India. Management Communication Quarterly, 21(2), 232-247. http://dx.doi.org/10.1177/0893318907308746

CSR Welt Weit. (2012). Japan: The role of CSR. Retrieved from http://www.csr-weltweit.de.en.country-profiles.profile/japan.index.nc.html

Ferraro, G. (2010). The cultural dimension of international business (6th ed.). Upper Saddle River, NJ: Pearson.

Fukukawa, K., \& Moon, J. (2004). A Japanese model of corporate social responsibility: A study of website reporting. Journal of Corporate Citizenship, 16, 45-59.

Fukukawa, K., \& Teramoto, Y. (2009). Understanding Japanese CSR: The reflections of managers in the field of global operations. Journal of Business Ethics, 85(1), 133-146. http://dx.doi.org/10.1007/s10551-008-9933-7

Higgins, C., \& Debroux, P. (2009). Globalization and CSR in Asia. Asian Business \& Management, 8(2), 125-127. http://dx.doi.org/10.1057/abm.2009.3

Himan no ko hatsu no gensho Monkasho chosa [Drop for the first time in the number of overweight children-Study of the Ministry of Education]. (2009, December 18). Yomiuri Shimbun.

Iwasawa, K. (1987, February 6). Shin fu-do ko 10 yureru shokutaku: Shoku midarete kodomo areru [New food paradigm No.10 Questionable meals on the table: Terrible diets lead to children's misbehavior]. Nihon KeizaiShinbum.

Japan Business Federation (Nippon Keidanren). (2007). Interim report on corporate philanthropic activities in the age of corporate social responsibility. http://www.keidanren.or.jp/English/policy/2007/103.html

Kagome Co., Ltd. (2009). Shakai kankyou houkokusho 2008 [Report for social and environmental activities 2008]. Retrieved from http://www.kagome.co.jp/kankyo/community.html

Keenleyside, H. L., \& Thomas, A. F. (1937). History of Japanese education and present educational system. Tokyo, Japan: Hakuseido.

Kireruko Shokuseikatsumo Ichiin [Impatient children: Diets as one factor]. (2000, February 25). Asahi Shimbun.

Kodomo ga kawatta 8 shokuiku [Children changed: No.8 Food education] (1999, July 9). Nishinippon Shimbun.

Konai boryoku to shoku no kankei [Relationship between school violence and diets]. (1985, April, 11). Asahi Shimbun.

Ligeti, G., \& Oravecz, A. (2009). CSR communication of corporate enterprises in Hungary. Journal of Business Ethics, 84(2), 137-149. http://dx.doi.org/10.1007/s10551-008-9678-3

Logsdon, J. M., Thomas, D. E., \& Van Buren, H. J. (2006). Corporate social responsibility in large Mexican firms. 
Journal of Corporate Citizenship, 21, 51-60.

Mah, C. L. (2010). Shokuiku: governing food and public health in contemporary Japan. Journal of Sociology, 46(4), 393-412. http://dx.doi.org/10.1177/1440783310384455

McFarlin, D., \& Sweeney, P. (2011). International management: Strategic opportunities and cultural challenges (4th ed.). New York, NY: Routledge.

McMillan, C. J. (1996). The Japanese industrial system (3rd ed.). Berlin, Germany: Walter de Gruyter. http://dx.doi.org/10.1515/9783110812879

Ministry of Agriculture, Forestry and Fishery [MAFF]. (n.d.). What is shokuiku [food education]? Retrieved from http://www.maff.go.jp/e/pdf/shokuiku.pdf

Ministry of Education, Culture, Sports, Science and Technology of Japan [MEXT]. (2003, September 10). Shokuni kannsuru sidou taisei no seibi ni tuite chukan houkoku [Interim report regarding the establishment of the food education system]. Retrieved from http://www.mext.go.jp/b_menu/shingi/toushin.htm

Ministry of Education, Culture, Sports, Science and Technology of Japan [MEXT]. (2010, December 22). Gakko kihonshosa Heisei 22 nendo: Todofukenbetsu gakko su [School statistics year 2010: The number of schools by prefecture]. Retrieved from http://www.mext.go.jp/b_menu/toukei/chousa01/kihon/1267995.htm

Ministry of Education, Culture, Sports, Science and Technology of Japan [MEXT]. (2012). Heisei 23 nenndo gakko hoken toukei chousa kakuteichi no kouhyo [Year 2011 Statistics of school children's health]. Retrieved from http://www.mext.go.jp/b_menu/toukei/chousa05/hoken/kekka/1268813.htm

Morsing, M., Schultz, M., \& Nielsen, K. U. (2008). The 'Catch 22' of communicating CSR: Findings from a Danish study. Journal of Marketing Communications, 14(2), 97-111. http://dx.doi.org/10.1080/13527260701856608

Mother and Child Health Foundation. (2006). Tokushu taidan: naze ima, shokuiku ka [Special interview: Why food education now?]. Retrieved from http://www.glico.co.jp/boshi/futaba/no70/con01_02.htm

Mother and Child Health Foundation. (2009). Boshikenko kyokai: Seturitsuno keii [Mother and Child Health Foundation: How the foundation was established]. Retrieved from http://www.glico.co.jp/boshi/tml.ft4.htm

Nielsen, A. E., \& Thomsen, C. (2009). Investigating CSR communicating in SMEs: A case study among Danish middle managers. Business Ethics: A European Review, 18(1), 83-93. http://dx.doi.org/10.1111/j.1467-8608.2009.01550.x

Okamoto, K. (2008). Shinkasuru CSR: Kigyo sekininron wo koeta henkakueno shiten [Evolving CSR: Reform perspective beyond corporate responsibility theory]. Tokyo, Japan: JIPM-Solution.

Podnar, K. (2008). Communicating corporate social responsibility. Journal of Marketing Communications, 14(2), 75-81. http://dx.doi.org/10.1080/13527260701856350

Porter, M. E., \& Kramer, M. R. (2006). Strategy \& society: The link between competitive advantage and corporate social responsibility. Harvard Business Review, 84(12), 78-92.

Soboleva, I. (2007). Corporate social responsibility: Global context and Russian realities. Problems of Economic Transition, 49(8), 82-95. http://dx.doi.org/10.2753/PET1061-1991490805

Sugihara, S. (1999, February 23). Shokuiku washoku no yosa ko ni tsutaeru [Food education: Pass on the good side of Japanese food to children]. Asahi Shimbun, p.19.

Takano, K. (2012, Summer). Tackling overweight problem: Healthy Japan was no exception. The International Institute for Asian Studies, 60, 15.

Tang, L., \& Li, H. (2009). Corporate social responsibility communication of Chinese and global corporations in China. Public Relations Review, 35(3), 199-212. http://dx.doi.org/10.1016/j.pubrev.2009.05.016

Tanimoto, K. (2006). CSR: Kigyoto shakaiwo kanngaeru [CSR: Thinking about corporations and the society]. Tokyo, Japan: NTT Publishing.

Tokoro, N. (2007). Stakeholders and corporate social responsibility (CSR): A new perspective on the structure of relationships. Asian Business \& Management, 6, 143-162. http://dx.doi.org/10.1057/palgrave.abm.9200218s

Toyo Keizai Shimpo Sha. (2009a). Kaishashikiho mijoujokaishaban: 2009nen Shimoki [Semi-annual business report of unlisted companies: 2009 second half]. Tokyo, Japan: Author.

Toyo Keizai Shimpo Sha. (2009b). Kaishashikiho shinshungo: 2010nen dai 1shuu [Quarterly business report of listed companies: Spring issue No. 1, 2010]. Tokyo, Japan: Author.

Wokutch, R. E. (1990). Corporate social responsibility Japanese style. Academy of Management Executive, $4(2), 56-74$. 